\title{
Uludağ (Bursa)'da Doğal Yayılış Gösteren Scilla bifolia L.'nin Bazı Morfolojik ve Fenolojik Özellikleri ile Yetişme Yerine Ait Gözlemler
}

\author{
Seydi Ahmet Kavaklı1 ${ }^{1}$, Ayşe Gül Sarikaya ${ }^{1 *}$ \\ ${ }^{1}$ Bursa Teknik Üniversitesi, Orman Fakültesi, Orman Müh. Bölümü, Bursa, Türkiye (ORCID*: 0000-0002-0641-4445)
}

(İlk Geliş Tarihi 1 Haziran 2019 ve Kabul Tarihi 18 Haziran 2019)

(DOI: $10.31590 /$ ejosat.574256)

\begin{abstract}
ATIF/REFERENCE: Kavaklı, S.A., \& Sarikaya, A.G.. (2019). Uludağ (Bursa)'da Doğal Yayılış Gösteren Scilla bifolia L.'nin Bazı Morfolojik ve Fenolojik Özellikleri ile Yetişme Yerine Ait Gözlemler. Avrupa Bilim ve Teknoloji Dergisi, (16), 454-459.

$\ddot{\mathbf{O} z}$

Birçok türü süs bitkisi olarak yetiştirilirken, gıda maddesi veya tıbbi olarak kullanılan türleri de bulunan Liliaceae familyasının, İç Batı, Batı ve Güney Anadolu'da bulunan, soğanlı çok yıllık otsu bir türü olan Scilla bifolia L. araştırma materyalini oluşturmaktadır. Uludağ (Bursa)'a yapılan keşif gezileri sonunda Scilla bifolia L.'nın bulunduğu noktalardan 15 adet örnek alan seçilmiş ve koordinatları alınmıştır. Türün çalışma sahasındaki morfolojik özelliklerini tespit etmek için her alandan 30'ar bitki örneği ve yumru toplanmıştır. Toplanan örneklerin dijital çap ölçer ile boyu, çiçek sayısı, çiçek sap uzunluğu, yaprak eni ve boyu, yaprak sayısı ve yumru eni ve boyu ölçülmüştür. Ayrıca toplanan yumruların ağırlığı dijital terazi ile ölçülmüştür. Türün çalışma alanındaki fenolojik zamanının tespiti için Mart ayı itibariyle arazi çalışmaları ile takibe alınmıştır. Yetişme yerinin topoğrafik, toprak, iklim, bitki örtüsü, rakım gibi bazı özelliklerine ait gözlemler yapılmıştır. Yapılan ölçümler sonucunda ortalama bitki boyu 167,30 mm, çiçek sap uzunluğu 12,63 mm, çiçek sayısı 5,73 adet, yaprak boyu 124,49 mm, yaprak eni 8,95 mm, yaprak sayısı 2,13 adet, yumru ağırlığı 0,86 gr, yumru boyu 13,30 mm ve yumru eni 10,43 mm olarak bulunmuştur. Fenolojik zamanına bakıldığında nisan-temmuz ayları arasında çiçeklenmenin olduğu tespit edilmiştir.
\end{abstract}

Anahtar Kelimeler: Scilla bifolia L., Morfolojik özellikler, Fenolojik özellikler, Uludă̆ (Bursa)

\section{Observations on Some Morphological and Phenological Feautures and Growing Area of Scilla bifolia L. Natural Distributed in Uludağ (Bursa)}

\begin{abstract}
While many species are grown as ornamental plants, the Liliaceae family, which contains foodstuffs or medically used species, is the research material of Scilla bifolia L., an herbaceous perennial herbaceous plant found in the Central West, West and South Anatolia. At the end of the discovery trips to Uludağ (Bursa), 15 sample areas were selected and coordinates were taken from the points where Scilla bifolia L. was found. In order to determine the morphological characteristics of some of the determined areas, plant samples were collected, 30 plant height, number of flowers, flower stem length, leaf width and length, number of leaves and tuber width and length were measured with digital diameter gauge. In addition, the weight of 30 tuber was measured by digital scale to determine the weight of the tuber. For the determination of the phenological time, as of March, it was followed by field studies. Observations were made on some characteristics such as topographic, soil, climate, vegetation, altitude. As a result of measurements, the average plant height was $167,30 \mathrm{~mm}$, the length of the flower stem was $12,63 \mathrm{~mm}$, the number of flowers was 5,73 ; the leaf length was $124,49 \mathrm{~mm}$,
\end{abstract}

\footnotetext{
* Sorumlu Yazar: Bursa Teknik Üniversitesi, Orman Fakültesi, Orman Müh. Bölümü, Bursa, Türkiye, ORCID: 0000-0002-0641-4445, aysegulsarikaya86@gmail.com
} 
the leaf width was $8,95 \mathrm{~mm} ., 86 \mathrm{~g}, 13.30 \mathrm{~mm}$ of tuber and $10.43 \mathrm{~mm}$ of tubers. Phenological time between April and July when the flowering is determined.

Keywords: Scilla bifolia L., Morphological features, Phenological characteristics, Uludağ (Bursa)

\section{Giriş}

Birçok türü süs bitkisi olarak yetiştirilirken, gıda maddesi veya tıbbi olarak kullanılan türleri de bulunan Liliaceae familyası, dünyada yaklaşık 250 cins ve bu cinslere ait 3500 kadar tür ile temsil edilmektedir. Türkiye'de 35 cinse ait 400 kadar türü bulunmaktadır (Seçmen vd. 1998). Liliaceae familyasına ait türler genellikle çok yıllık otsu olarak nadiren de odunsu çalılar olup, gövdeleri dik ve tırmanıcı, yaprakları linearlanseolat, kaidede ya da gövdede alternat dizilişli, çiçek durumu rasemoz, tek veya kimoz şeklinde, periant 2 dairede serbest veya birleşik 6 parçalı, parçaları birbirine benzer ve gösterişli, korona var ya da yoktur. Ovaryum alt veya orta durumlu, 3 lokuluslu ve karpelli, tohum taslakları çok sayıdadır (Seçmen vd.2004). Kozmopolit bir familya olan Liliaceae çoğunlukla tropikal ve ılıman bölgelerde doğal yayılış göstermektedir (Seçmen vd. 1998). Lilium, Allium, Ornithogalum, Scilla, Colchicum, Tulipa, Narcissus ve Fritillaria gibi birçok cinsi içermektedir.

Scilla L. cinsinin, ülkemizde 19 taksonu bulunmaktadır (Güner, 2012). İç Batı, Batı ve Güney Anadolu'da bulunan, soğanlı çok yıllık otsu bir bitki olan Scilla bifolia L. araştırma materyalini oluşturmaktadır. Scilla bifolia L. Türkçe'de orman sümbülü, iki yapraklı sümbül, alp ada soğanı ve kampana çiçeği olarak adlandırılmaktadır (Güner, 2012; Özhatay vd., 2012; Karaca, 2008; Kaynak vd., 2008). Bu çalışmanın amacı Uludağ (Bursa)'da doğal yayılış gösteren Scilla bifolia L.'nin bazı morfolojik ve fenolojik özelliklerini tespit etmek ve yayılış alanı özelliklerine ait gözlemleri ortaya koymaktır.

\section{Materyal ve Metot}

Uludağ (Bursa)'da doğal yayılış gösteren Scilla bifolia L. araştırma materyalini oluşturmaktadır. 2018-2019 vejetasyon dönemi içerisinde, Uludağ (Bursa)'a yapılan keşif gezileri sonunda tespit edilen Scilla bifolia L.'nın bulunduğu noktaların Garmin GPS Map $64 \mathrm{~S}$ ile koordinatları alınmış daha sonra bu alanlar içerisinde örnek sahaların alınacağı yerler belirlenmiştir. Örnek alanların seçiminde türün alanda hakim tür olmasına, türe ait bireylerin belli bir olgunluğa gelmiş olmasına, sağlıklı olmasına, farklı yetişme ortamlarını temsil etmesine ve insan etkisinden olabildiğince uzak olmasına dikkat edilmiştir. Daha sonra 20 x $20 \mathrm{~m}$ boyutlarında farklı 15 örnek alanlar alınmış ve koordinatları kaydedilmiştir (Şekil 1), (Tablo 1). Belirlenen alanlardan bir kısmı morfolojik özelliklerini tespit etmek amacıyla kullanılmak üzere ve diğer kısmı herbaryumda saklanmak üzere bitki örnekleri toplanmıştır. Morfolojik ölçümlerini hesaplamak için dijital çap ölçer ile 30'ar adet bitki boyu, çiçek sayısı, çiçek sap uzunluğu, yaprak eni ve boyu, yaprak sayısı ve yumru eni ve boyu ölçülmüştür. Ayrıca yumru ağırlığını belirlemek için 30 adet yumrunun ağırlığı dijital terazi ile ölçülmüştür. Fenolojik zamanının tespiti için Mart ayı itibariyle arazi çalışmalarına başlanmıştır. Bitki takibe alınarak çiçeklenme zamanı saptanmıştır. Yetişme yerinin topoğrafik, toprak, iklim, bitki örtüsü, rakım gibi bazı özelliklerine ait gözlemler yapılmıştır.

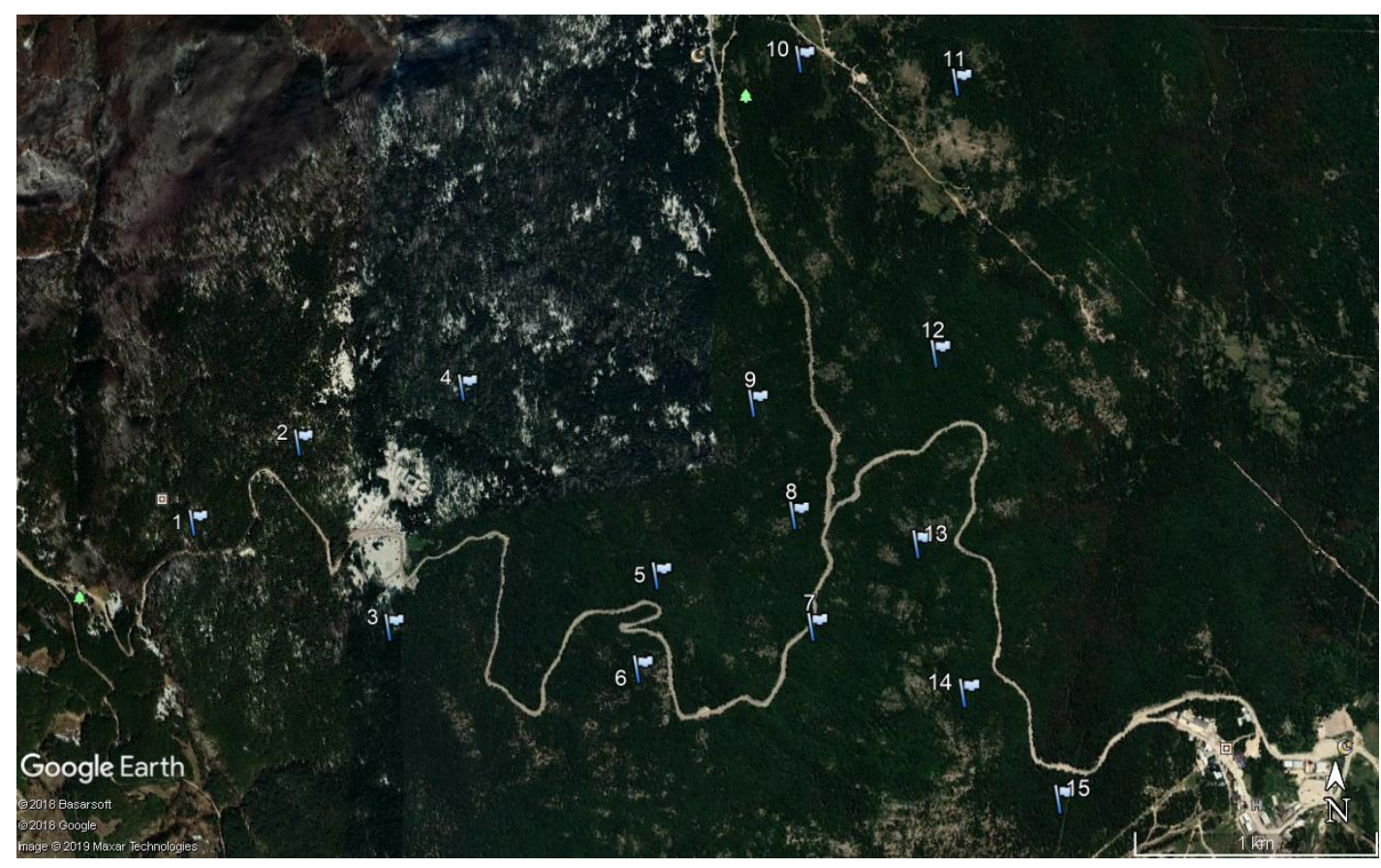

Şekil 1. Çalışma sahası içindeki belirlenen örnek alanlar 
Tablo 1. Çalışma sahası içindeki belirlenen örnek alanların koordinatları

\begin{tabular}{cl}
\hline $\begin{array}{c}\text { Örnek } \\
\text { Alan No }\end{array}$ & Örnek Alanların Koordinatları \\
\hline 1. & $40^{\circ} 06.860^{\prime} \mathrm{K}, 29^{\circ} 04.809^{\prime} \mathrm{D}$ \\
2. & $40^{\circ} 07.049^{\prime} \mathrm{K}, 29^{\circ} 05.146^{\prime} \mathrm{D}$ \\
3. & $40^{\circ} 06.827^{\prime} \mathrm{K}, 29^{\circ} 05.440^{\prime} \mathrm{D}$ \\
4. & $40^{\circ} 07.175^{\prime} \mathrm{K}, 29^{\circ} 05.657^{\prime} \mathrm{D}$ \\
5. & $40^{\circ} 06.644^{\prime} \mathrm{K}, 29^{\circ} 06.226^{\prime} \mathrm{D}$ \\
6. & $40^{\circ} 06.674^{\prime} \mathrm{K}, 29^{\circ} 06.277^{\prime} \mathrm{D}$ \\
7. & $40^{\circ} 06.555^{\prime} \mathrm{K}, 29^{\circ} 06.376^{\prime} \mathrm{D}$ \\
8. & $40^{\circ} 06.888^{\prime} \mathrm{K}, 29^{\circ} 06.643^{\prime} \mathrm{D}$ \\
9. & $40^{\circ} 07.137^{\prime} \mathrm{K}, 29^{\circ} 06.525^{\prime} \mathrm{D}$ \\
10. & $40^{\circ} 07.914^{\prime} \mathrm{K}, 29^{\circ} 06.665^{\prime} \mathrm{D}$ \\
11. & $40^{\circ} 07.858^{\prime} \mathrm{K}, 29^{\circ} 07.126^{\prime} \mathrm{D}$ \\
12. & $40^{\circ} 07.245^{\prime} \mathrm{K}, 29^{\circ} 07.051^{\prime} \mathrm{D}$ \\
13. & $40^{\circ} 06.830^{\prime} \mathrm{K}, 29^{\circ} 06.985^{\prime} \mathrm{D}$ \\
14. & $40^{\circ} 06.516^{\prime} \mathrm{K}, 29^{\circ} 07.106^{\prime} \mathrm{D}$ \\
15. & $40^{\circ} 06.292^{\prime} \mathrm{K}, 29^{\circ} 07.370^{\prime} \mathrm{D}$ \\
\hline
\end{tabular}

\section{Araştırma Sonuçları ve Tartışma}

Uludağ (Bursa)'da doğal yayılış gösteren Scilla bifolia L.'nin bazı morfolojik ve fenolojik özellikleri tespit edilmiştir. Morfolojik ölçümlerini hesaplamak için dijital çap ölçer ile 30'ar adet bitki boyu, çiçek sayısı, çiçek sap uzunluğu, yaprak eni ve boyu, yaprak sayısı ve yumru eni ve boyu ölçülmüştür. Ortalama bitki boyu 167,30 mm, çiçek sap uzunluğu 12,63 mm, çiçek sayıs 5,73 adet, yaprak boyu 124,49 mm, yaprak eni $8,95 \mathrm{~mm}$, yaprak sayısı 2,13 adet, yumru ağırlı̆̆ 0,86 gr, yumru boyu $13,30 \mathrm{~mm}$ ve yumru eni 10,43 mm olarak bulunmuştur (Şekil 2), (Tablo 2). 


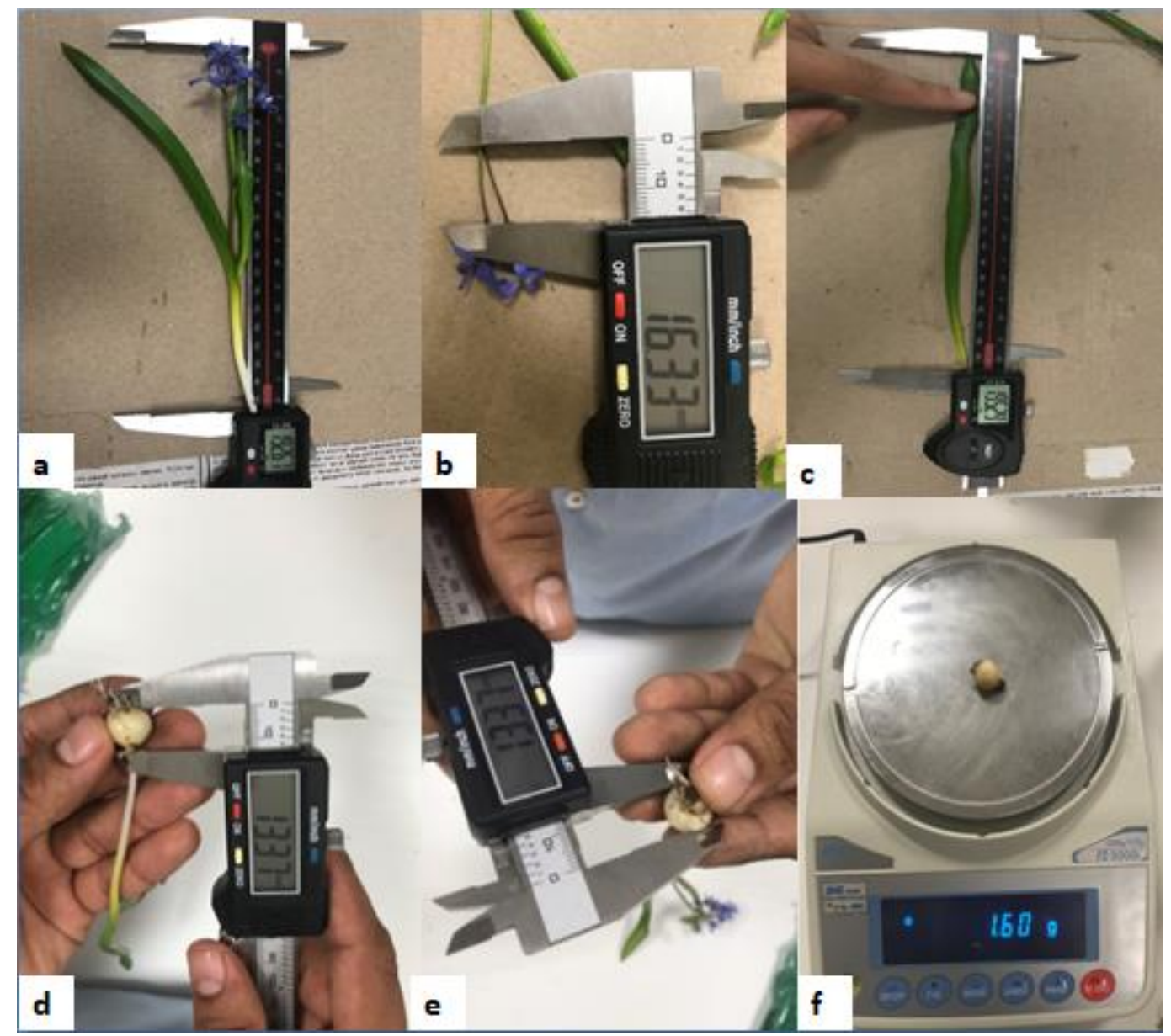

Şekil 2. Scilla bifolia L.'nin bazı morfolojik ölçümlerine ait görüntüler (a: Bitki boyu, b: Çiçek sap uzunluğu, c: Yaprak boyu, d: Soğan boyu, e: Sŏgan eni, $f$ : Soğan ă̆ırlı̆̆l)

Tablo 2. Scilla bifolia'nın morfolojik ölçüm değerleri

\begin{tabular}{lcc}
\hline & Min.-Mak. & Ortalama \\
\hline Bitki Boyu & $107,65-234,08 \mathrm{~mm}$ & $167,30 \mathrm{~mm}$ \\
Çiçek Sap Uzunluğu & $5,09-37,54 \mathrm{~mm}$ & $12,63 \mathrm{~mm}$ \\
Çiçek Sayısı & $2-14$ adet & 5,73 adet \\
Yaprak Eni & $4,92-14,14 \mathrm{~mm}$ & $8,95 \mathrm{~mm}$ \\
Yaprak Boyu & $92,98-195,29 \mathrm{~mm}$ & $124,49 \mathrm{~mm}$ \\
Yaprak Sayısı & $1(-2)-7$ adet & $2,13 \mathrm{adet}$ \\
Soğan Eni & $6,92-15,36 \mathrm{~mm}$ & $10,43 \mathrm{~mm}$ \\
Soğan Boyu & $9,68-16,50 \mathrm{~mm}$ & $13,30 \mathrm{~mm}$ \\
Soğan Ă̆ırlığı & $0,34-2,5 \mathrm{gr}$ & $0,86 \mathrm{gr}$ \\
\hline
\end{tabular}

Fenolojik zamanına bakıldığında ilk çiçeklenmenin nisan başı başladığı, mayıs-haziran aylarında tam çiçeklenmenin görüldüğü ve temmuz ayının sonlarında çiçeklenmenin sona erdiği gözlemlenmiştir. Çiçek renginin mor, mavimsi-mor ve leylak-mavi renklerde olduğu belirlenmiştir (Şekil 3). 


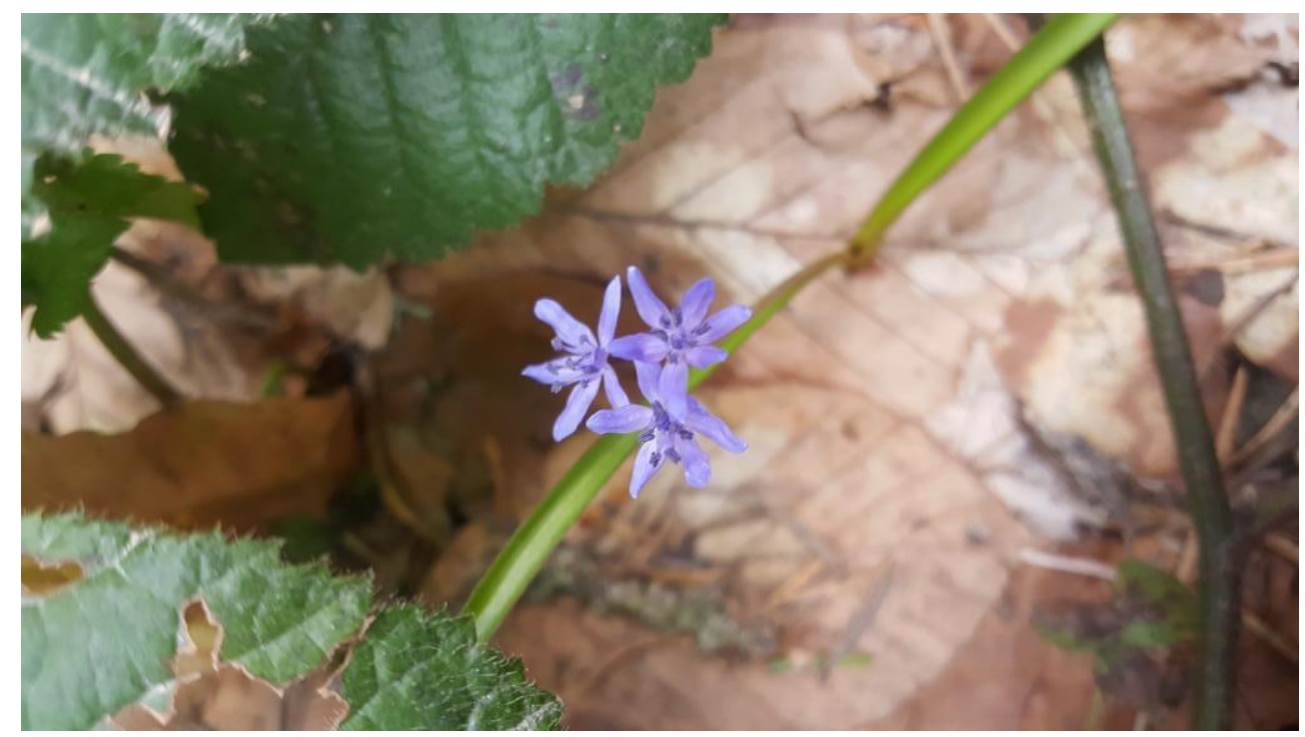

Şekil 3. Scilla bifolia L.'nin genel görünümü ve çiçekleri

Yetişme yeri özelliklerine bakıldığında 1400-1710 m rakımlar arasında, göknar, kayın ve çam orman altlarının açıklıklarında, çayırlık alanlar, kayalık taşlık yamaçlar, orman sınırının bittiği yol kenarı açıklıklarında ve üst rakımlarda karın eridiği eğimli ve düz alanlarda yayılış gösterdiği tespit edilmiştir. Uludağ'ın Akdeniz ve 1lıman iklimin etkisinde olduğu alanların yanı sıra üst rakımlara doğru daha yağışlı ve soğuk iklim özelliklerinde de yetiştiği görülmüştür. Türün yetişme yerlerinde kırmızı sarı podzolik topraklarkahverengi orman toprakları, yüksek dağ çayır toprakları ve organik toprakları tercih ettiği gözlemlenmiştir. Uludağ (Bursa)'da doğal yayılış gösteren Scilla bifolia L.'nin bazı morfolojik ve fenolojik özellikleri tespit edilmiş ve bu konuda yapılan benzer çalışmalarla karşılaştırılmıştır (Tablo 3 ve Tablo 4).

Tablo 3. Scilla bifolia'nın morfolojik ölçümlerinin yapılan diğer çalışmalar ile karşılaştırılması

\begin{tabular}{|c|c|c|c|c|c|}
\hline & $\begin{array}{l}\text { Çalışmada } \\
\text { Min.-Mak. }\end{array}$ & TR Florası & $\begin{array}{l}\text { Kaynak vd., } \\
2008\end{array}$ & $\begin{array}{c}\text { Özdemir ve } \\
\text { Alçıtepe, } 2010\end{array}$ & $\begin{array}{c}\text { Özhatay vd., } \\
2012\end{array}$ \\
\hline Bitki Boyu & $107,65-234,08 \mathrm{~mm}$ & - & - & - & - \\
\hline $\begin{array}{l}\text { Çiçek Sap } \\
\text { Uzunluğu }\end{array}$ & $5,09-37,54 \mathrm{~mm}$ & Min. $50 \mathrm{~mm}$ & $5-37 \mathrm{~cm}$ & $6-40 \mathrm{~cm}$ & - \\
\hline Çiçek Sayısı & 2-14 adet & $1-15(-25)$ adet & $1-25$ adet & $1-5$ adet & - \\
\hline Yaprak Eni & $4,92-14,14 \mathrm{~mm}$ & $(1,5) 3-5 \mathrm{~mm}$ & - & $1,5-9 \mathrm{~mm}$ & - \\
\hline Yaprak Boyu & $92,98-195,29 \mathrm{~mm}$ & $(4) 7-19(-35) \mathrm{cm}$ & $4-35 \mathrm{~cm}$ & $2,5-16 \mathrm{~cm}$ & - \\
\hline Yaprak Sayısı & 1(-2)-7 adet & 1(-2)-7 adet & $1-7$ adet & $2(-1)$ adet & - \\
\hline Soğan Eni & $6,92-15,36 \mathrm{~mm}$ & $0,5-2 \mathrm{~cm}$ & $2-3 \mathrm{~mm}$ & $2,5 \mathrm{~cm}$ & $0,5-2 \mathrm{~cm}$ \\
\hline Soğan Boyu & $9,68-16,50 \mathrm{~mm}$ & - & - & - & - \\
\hline Soğan Ağırlığı & $0,34-2,5 \mathrm{gr}$ & - & - & - & - \\
\hline
\end{tabular}

Scilla bifolia'nın morfolojik ölçümlerinin yapılan diğer çalışmalar ile karşılaştırıldığında, çalışmamızdan farklılık gösterdiği ve sadece yaprak sayısı adetlerinin bezer olduğu tespit edilmiştir. Farklılığın sebeplerinin yayılış alanlarının, ikliminin, toprak özelliklerinin, topoğrafik yapısının ve rakımının farklı olmasından kaynaklandığı düşünülmektedir.

Tablo 4. Scilla bifolia'nın fenolojik özelliklerinin yapılan diğer çalışmalar ile karşılaştırılması

\begin{tabular}{|c|c|c|c|c|c|c|c|}
\hline $\begin{array}{c}\text { Aylar } \\
\text { Çalıșmalar }\end{array}$ & Şubat & Mart & Nisan & Mayıs & Haziran & Temmuz & Ăgustos \\
\hline Çalışmada & & & $\mathrm{X}$ & $\mathrm{X}$ & $\mathrm{X}$ & $\mathrm{x}$ & \\
\hline Andiç, 1985 & & & & & & $\mathrm{x}$ & $\mathrm{x}$ \\
\hline Altınçekiç, 1996 & $\mathrm{x}$ & $\mathrm{x}$ & $\mathrm{X}$ & $\mathrm{X}$ & $\mathrm{x}$ & & \\
\hline Karaca, 2008 & & $\mathrm{x}$ & $\mathrm{x}$ & $\mathrm{x}$ & $\mathrm{x}$ & & \\
\hline Kaynak vd., 2008 & $\mathrm{X}$ & $\mathrm{x}$ & $\mathrm{x}$ & $\mathrm{x}$ & $\mathrm{x}$ & $\mathrm{x}$ & \\
\hline Özhatay vd., 2012 & $\mathrm{x}$ & $\mathrm{x}$ & $\mathrm{x}$ & $\mathrm{x}$ & $\mathrm{x}$ & $\mathrm{x}$ & \\
\hline $\begin{array}{c}\text { K1liçaslan ve } \\
\text { Dönmez, } 2016\end{array}$ & $\mathrm{x}$ & $\mathrm{X}$ & $\mathrm{X}$ & & & & \\
\hline
\end{tabular}


Scilla bifolia'nın fenolojik özelliklerinin yapılan diğer çalışmalar ile karsılaştıııldığında, Altınçekiç (1996); Kaynak vd.(2008); Özhatay vd. (2012) çalışmalarıyla nisan, mayıs haziran ve temmuz ayları ile benzerlik gösterdiği, Karaca (2008) ile nisan, mayıs ve haziran aylarının, Andiç (1985) ile temmuz ayının ve Kılıçaslan ve Dönmez (2016) ile nisan ayının benzer olduğu tespit edilmiştir.

\section{Sonuç}

Bu çalışma ile Uludağ (Bursa)'da doğal yayılış gösteren Scilla bifolia L.'nin bazı morfolojik ve fenolojik özelliklerini tespit etmek ve yayılış alanı özelliklerine ait gözlemleri ortaya konmuştur. Soğanlı bitkiler, ekonomik, ekolojik, estetik, tıbbi ve aromatik açıdan önem taşımaktadır. Çiçeklenme zamanının belirtilmesi ile toplama zamanının bilinmesi, özellikle peyzaj çalışmalarında kullanımı ve arıcılıkta değerlendirilmesi açısından kolaylık sağlayacağı düşünülmektedir. Ayrıca Scilla bifolia'nın tıbbi ve aromatik öneminin ortaya konması için kapsamlı çalışmaların yapılması tavsiye edilmektedir. Özellikle ilaç ve gıda endüstrisi açısından etken maddelerin elde edilmesi ile ilaç yapımında yada gıdalarda koruyucu olarak yada renklendirici olarak kullanılabileceği düşünülmektedir.

\section{Kaynakça}

Altınçekiç, H., 1996. Çilingoz Koyu (Trakya) Peyzaj Planlaması Amacına Yönelik Bitki Materyalinin Saptanması. İstanbul Üniversitesi, Fen Bilimleri Enstitüsü, Doktora Tezi. İstanbul.

Andiç, C 1985. Erzurum yöresi doğal çayır mera ve yayla vejetasyonlarında mevcut bitki türleri, bunların hayat formları ve çiçeklenme periyotları. Atatürk Üniversitesi Ziraat Fakültesi Dergisi, 16: 85-104.

Güner, A., 2012. Türkiye Bitkileri Listesi, Damarlı Bitkiler. Nezahat Gökyiğit Botanik Bahçesi Yayınları, 1290 s, İstanbul.

Karaca, A., 2008. Aydın Yöresinde Bal Arılarının (Apis Mellifera L.) Yararlanabileceği Bitkiler ve Bazı Özellikleri. ADÜ Ziraat Fakültesi Dergisi, 5(2):39-66.

Kaynak, G., Daşkın R., Yılmaz, Ö., 2008. Bursa Bitkileri. Uludağ Üniversitesi Yayınları, 865 s.

Kılıçaslan, N., Dönmez, Ş., 2016. Göller bölgesinde doğal olarak yetişen soğanlı bitkilerin peyzaj mimarlığında kullanımı. Türkiye Ormancilık Dergisi, 17(1): 73-82.

Özdemir, C., Alçıtepe, E., 2010. Scilla bifolia L. (Liliaceae) Üzerinde Morfolojik ve Anatomik Bir İnceleme. Kastamonu Üni., Orman Fakültesi Dergisi, 11 (2): 126-129.

Özhatay, N., Koçyiğit, M., Bona, M., 2012. İstanbul'un Ballı Bitkileri. 264 s.

Seçmen, Ö., Gemici, Y., Görk, G., Bekat, L., Leblebici, E., 1998. “Tohumlu Bitkiler Sistematiği”, Ege Üniv. Fen Fak. Kitaplar Serisi, İzmir, $110 \mathrm{~s}$.

Seçmen, Ö., Gemici, Y., Görk, G., Bekat, L., Leblebici, E., 2004. “Tohumlu Bitkiler Sistematiği”, Ege Üniv. Fen Fak. Kitaplar Serisi, İzmir, $116 \mathrm{~s}$.

Tan, A., 1992. Türkiye'de Bitkisel Çeşitlilik ve Bitki Genetik Kaynakları (Plant Diversity and Plant Genetic Reources in Turkey), Anadolu, 2 (199); 50-64. 